\title{
Pregnancy Complicated Cushing Syndrome Secondary to Adrenal Adenoma
}

\begin{abstract}
Keywords: Cushing syndrome; Pregnancy; Adrenal adenoma
Abstract

We report a case of Cushing syndrome secondary to adrenal adenoma and the fetus showing nonreactive fetal heart rate pattern on non-stress test some days with general movements (GMs) negative. The tumor was confirmed at $31+5$ weeks of pregnancy and removed surgically one month after the birth. The fetus showed nonreactive fetal heart rate pattern on non-stress test for nearly a week and was born by caesarean section at $33+6$ weeks of gestation. Five months after birth, the fetus had the test of GMs which was normal.
\end{abstract}

\section{Introduction}

Cushing's syndrome (CS) is a disorder caused by high excessive exposure to cortisol that is associated with significant maternal and fetal complications including hypertension, diabetes, heart failure, pulmonary edema, spontaneous abortion, preterm labor, fetal intrauterine growth, retardation, miscarriage and stillbirth [13]. In contrast to the general population, the most common cause of CS during pregnancy is adrenal adenoma followed by pituitary etiology, pregnant situation and adrenal carcinoma [4-6]. Although the mechanism underlying this condition remains unclear, it could be related to less ovarian function interference in pure cortisol secreting adrenal adenomas. Cushing's syndrome during pregnancy is a rare metabolic condition that is difficult to diagnose [1,7-9]. The diagnosis of this disorder during pregnancy is challenging because the typical symptoms for Cushing's syndrome mimic those of normal pregnancy. The diagnosis is usually made based on clinical presentations, laboratory workup and imaging findings.

Even after detection of CS, the management of CS remains controversial. It can be managed medically with metyrapone and cabergoline, surgically such as Laparoscopic adrenalectomy, or conservatively [4,7,10-12]. Many literatures advocate active treatment in controlling serum cortisol levels. Whether active treatment or conservative treatment could ensure a safe maternal and fetal outcome is still in research. Here we reported a pregnant woman who developed Cushing's syndrome received conservative management and we would like to discuss the diagnosis and management of CS during pregnancy.

\section{Case Report}

A 31-year-old primiparous (G1P0) woman was referred to our hospital at $15+5$ weeks of pregnancy for dissatisfied blood glucose. Her medical history revealed mild high blood pressure and mild diabetes mellitus controlled by metformin, She came for pre-pregnancy checkup in 2012 and found rudimentary horn of uterus from ultrasonography and MRI. This time, her glycosylated hemoglobin $(\mathrm{HbAlc}$ ) was $6.9 \%$ (Normal $\leq 6.5 \%)$. Her fasting plasma
Journal of

Hematology \& Thrombosis

\author{
Shuang-Ping Liu, Dong-Ling Wu, Hai-Dong Cheng ${ }^{\#}$ \\ and Yu Xiong \\ Obstetrics and Gynecology Hospital, Fudan University, Shanghai \\ 200011, China \\ \#These two authors contributed equally \\ *Address for Correspondence: \\ Yu Xiong and Hai-Dong Cheng, Obstetrics and Gynecology \\ Hospital, Fudan University, 128 Shenyang Road, Shanghai 200011, \\ China, Tel: +86 216345 5050; Fax: +86 216345 5090; E-mail: \\ xiongyu1535@163.com; hdcheng_2003@163.com \\ Submission: 14 March, 2017 \\ Accepted: 30 March, 2017 \\ Published: 10 April, 2017 \\ Copyright: $\odot 2017$ Liu SP. This is an open access article distributed \\ under the Creative Commons Attribution License, which permits \\ unrestricted use, distribution, and reproduction in any medium, provided \\ the original work is properly cited.
}

glucose ranged 3.8-6.1 $\mathrm{mmol} / \mathrm{L}$ and postprandial blood glucose ranged 3.9-7.8 $\mathrm{mmol} / \mathrm{L}$. Her blood pressure ranged 117-142/78$94 \mathrm{mmHg}$ controlled by labetalol. Because of the ketonuria and uncontrolled hyperglycemia, she was admitted. We initially managed her blood glucose by diet, exercise and medicine and then switched to insulin for better blood glucose control.

At 29 weeks of pregnancy, she developed proximal muscle weakness especially on the lower limbs. The basic biochemical examination was normal except for hypokalemia (potassium was $2.5 \mathrm{mmol} / \mathrm{L}$ ) and potassium chloride was administered. Thyroid hormones were below normal range. Thyrotropin (TSH) was $0.25 \mu \mathrm{IU} / \mathrm{ml}$ with normal ranges between $0.60-6.48 \mu \mathrm{IU} / \mathrm{ml}$. Free Triiodothyronine (FT3) was $1.7 \mathrm{pmol} / \mathrm{l}$ with normal ranges between 3.14-5.04 pmol/l. Free Thyroxine (FT4) was $6.99 \mathrm{pmol} / \mathrm{l}$ with normal ranges between 9.12-15.71 pmol/l. She suffered from hypothyroidism and was taking $25 \mu \mathrm{g}$ of levothyroxine. The patient was taking calcium tablet two pills one time a day.

At $31+5$ weeks of pregnancy, the ultrasonography of the adrenal gland was performed cause of repeat hypokalemia and typical cushingoid signs including truncal obesity, moon face, prominent dorsal and supraclavicular fat depositions, acne, and purple striae on abdomen. Ultrasonography revealed a round tumor with a size of $30 \times 25 \mathrm{~mm}$ around the right adrenal gland. Then, Cushing's syndrome related auxiliary examinations were tested one by one.

Serum cortisol concentration after morning awakening was $908.65 \mathrm{nmol} / \mathrm{L}$ with normal ranges between 185-624 nmol/l and in the afternoon $723.31 \mathrm{nmol} / \mathrm{L}$ with normal concentrations below $276.4 \mathrm{nmol} / \mathrm{l}$. The 17 -hydroxycorticosteroid $24 \mathrm{~h}$ urinary excretion was $30.75 \mathrm{mg} / 24 \mathrm{~h}$ with normal ranges between $2-8 \mathrm{mg} / 24 \mathrm{~h}$ and 17-ketone steroids $21.78 \mathrm{mg}$ with normal ranges between 6-14 mg/24 h. The plasma adrenocorticotropic hormone (ACTH) concentration at 8 am and at $4 \mathrm{pm}$ were both less than $1.00 \mathrm{pg} / \mathrm{ml}$ with normal range between $5-60 \mathrm{pg} / \mathrm{ml}$.

At 32 week 4 day weeks of pregnancy, vanillyl-mandelic acid (VMA) $24 \mathrm{~h}$ urinary excretion was $1.90 \mathrm{mg} / 24 \mathrm{~h}$ with normal ranges 
Citation: Liu SP, Wu DL, Cheng HD, Xiong Y. Pregnancy Complicated Cushing Syndrome Secondary to Adrenal Adenoma. J Hematol Thromb 2017;3(1): 3.

between $2-7 \mathrm{mg} / 24 \mathrm{~h}$ and Homovanillic acid (HVA) $1.4 \mathrm{mg} / 24 \mathrm{~h}$ with normal ranges between $2-7 \mathrm{mg} / 24 \mathrm{~h}$. The plasma renin activity was $0.40 \mathrm{ng} / \mathrm{ml} / \mathrm{h}$ in a sitting position with normal range between 0.93 $6.53 \mathrm{ng} / \mathrm{ml} / \mathrm{h}$. Angiotensin II was more than $800.00 \mathrm{Pg} / \mathrm{ml}$ in a sitting position with normal range between 55.3-115.3 Pg/ml. Aldosterone was $191.53 \mathrm{Pg} / \mathrm{ml}$ in a sitting position with normal range between 65.2-295.7 Pg/ml. The Magnetic Resonance Imaging (MRI) of abdomen revealed a round lesion recognized of adrenal adenoma in the right adrenal gland with size of $34 \times 20 \times 26 \mathrm{~mm}$ (Figure 1).

At 33 weeks of pregnancy, the fetus showed nonreactive fetal heart rate pattern on non-stress test for nearly one week on account of the fear of the patient and her husband about termination of pregnancy. We used Mucosolvan $1.0 \mathrm{~g}$ one time a day for two days to prevent
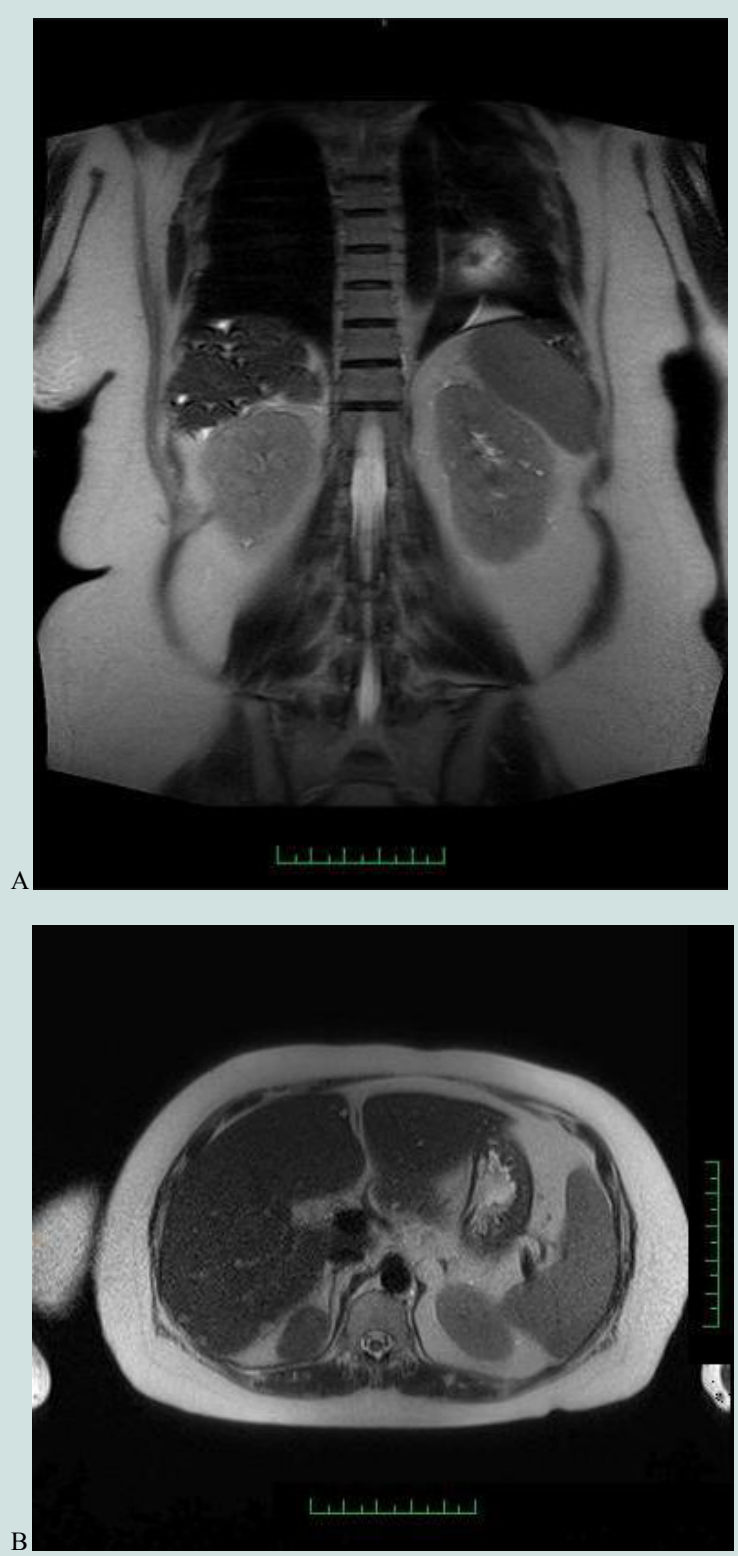

Figure 1: Magnetic resonance imaging of the adrenals revealed a homogeneous nodule in the right adrenal region. The arrow indicates the right adrenal mass. A) T2 weighted image at coronal plane. B) T1 weighted image on transverse section. respiratory distress syndrome and closely monitoring the fetal heart rate. A female neonate was born by caesarean section at 33 week 6 day weeks of pregnancy. The Apgar score at 1 and 5 min was nine points at both times. Birth weight was $1670 \mathrm{~g}$ and was appropriate for the gestational age. Due to wet lung of the newborn and low birth weight, the newborn was admitted to Neonatology Department. The basic biochemical examination was normal. On the secondary day we started enteral feeding with good tolerance and a normal body weight gain. Mild neonatal jaundice occurred in the hospital and required phototherapy. On the $30^{\text {th }}$ day of life the newborn was discharged home in a good condition with a body weight of $2000 \mathrm{~g}$. Five months after birth, the fetus had the test of general movements (GMs) and reveal normal. GMs is an early utility prediction of serious neurological development outcomes such as cerebral palsy.

On the $35^{\text {th }}$ day after delivery, the patient was admitted to the Ruijin hospital.

After preoperative preparation, laparoscopic right adrenalectomy was performed. The histopathological result after surgery revealed a cortical adenoma of the right adrenal gland (diameter of 30 $\mathrm{mm}$ ). Directly after the surgery, a hydrocortisone substitution was introduced. The patient was dismissed from hospital on the seventh postoperative day. The patient was referred to the outpatient clinic for later follow-up.

\section{Discussion}

Although Cushing's syndrome during pregnancy is extremely rare-to date, less than 140 cases have been records, but it is associated with significant maternal and fetal morbidity $[1,4]$. In addition, the diagnosis may pose a challenge because the typical symptoms of Cushing's syndrome may also occur in normal pregnant women. Therapy for Cushing's syndrome during pregnancy is significantly limited in view of the very limited experience.

The most common cause of CS during pregnancy is adrenal adenoma, followed by pituitary etiology, and adrenal carcinoma. Of the total number of CS cases, adrenal adenomas comprise about half of cases in pregnancy in contrast with pituitary-dependent disease predominates in the non-pregnancy women $[2,4,11]$. The reason might be related to less ovarian function interference in pure cortisolsecreting adrenal adenomas [3,11]. In addition, several cases of pregnancy-dependent CS have been reported and the most commonly mechanism involves aberrant LHCGR expression $[2,9,13]$. Pregnancy is associated with marked changes in the hypothalamus-pituitaryadrenal (HPA) axis, resulting in a state of increasing HPA function $[4,11]$. The increases in plasma cortisol are noted as early as 11 weeks of gestation. In this case, the MRI of abdomen revealed polycystic change in the liver and kidney two years ago. She developed typical cushingoid signs at 29 weeks of gestation. The MRI of abdomen revealed a round lesion recognized of adrenal adenoma in the right adrenal gland. Maybe pregnancy stimulates adrenal hyperplasia to form adrenal adenoma.

The diagnosis of the CS in pregnancy is more challenging than in the non-pregnant state and is confounded by the similar symptoms and normal pregnancy rise in serum and urine cortisol. Pregnant women without CS may show symptoms suggestive of hypercortisolism, such as central weight gain, edema, moon facies, abdominal striae, hypertension, pre-eclampsia, glucose intolerance 
and gestational diabetes $[2-4,9,11,12]$. In addition, the presence of hyperpigmented violaceous striae of typically large and purple as supposed to skin-colored striae, proximal myopathy, hirsutism, acne and pathologic fractures may help to distinguish CS from normal pregnancy symptoms $[4,11]$. In this case, the patient presented with hypertension, diabetes, muscle weakness, moon face, acne and purple striae on abdomen.

Making a biochemical diagnosis of Cushing's syndrome in pregnancy is also not straightforward cause of 2 -fold to 3 -fold increasing in maternal plasma cortisol concentrations during pregnancy which may overlap those seen in CS $[4,11,12]$. The best screening test in pregnancy is a 24 hour urine collection for free cortisol [14]. UFC concentrations greater than 3 times the upper normal limit can be considered to be consistent with pathological hypercortisolism $[15,16]$. In addition, the dexamethasone suppression test in pregnant women has a higher false positive rate due to blunted response to dexamethasone $[1,11,12]$. However, the diurnal rhythm of plasma cortisol is preserved in pregnancy, so identifying a lack of diurnal variation of cortisol is helpful in establishing the diagnosis of CS $[1,11]$. To conclude, current data suggest that a combination of UFC concentrations greater than 3 times the upper normal limit and absent diurnal variation of plasma cortisol levels could be the clues of diagnosis of CS in pregnancy.

Once biochemical evidence of CS is confirmed, the next step is to determine the etiology and imageological diagnosis to differentiate between pituitary adenomas, adrenal tumor and other rarer causes. Ultrasonography is first examination method selected to patient to scan abdomen inspection. Although further studies are needed to evaluate the safety of MRI in pregnancy, it is safer than CT. MRI tests should be carefully carried out for evaluation of the adrenal glands and pituitary because it is FDA category C. In this case of our patient, critical for diagnosis was the improper concentration of serum cortisol in the blood and the round rumor which was found around the right adrenal gland during ultrasonographic examination and MRI.

Both the mother and the fetus have severe complication induced by CS. Maternal complications include hypertension, pre-eclampsia, impaired glucose tolerance, diabetes mellitus, myopathy, cardiac failure, pulmonary edema and opportunistic infections. The fetus may suffer from miscarriage, intrauterine growth retardation, pre-term deliveries and stillbirth $[2,3,7,9]$. Fetal adrenal suppression occurs rarely suggesting that placental degradation of cortisol protects the fetus [11]. In this case, the fetus showed nonreactive fetal heart rate pattern on non-stress test for nearly a week and GMs revealed normal at five months after birth. The non-stress test showed the activity of the fetal brain. Nonreactive fetal heart rate pattern revealed the fetus having intrauterine anoxia or cerebral palsy, but the fetus was normal after birth. The maternal thyroid function tests revealed central hypothyroidism. The fetal brain activity was suppressed, so the nonstress test showed nonreactive fetal heart rate pattern. Throughout this case, we might look forward to treatment instead of termination of pregnancy when the pregnancy complicated CS. Of course, it is crucial to strengthen the maternal-fetal monitoring.

Management of the pregnancy patient with CS includes identifying the etiology and establishing proper therapy. The right therapy is crucial for the maternal and fetal prognosis. Surgical treatment is reported to be the mainstay of therapy of CS in pregnancy $[1,9,12,17]$. Laparoscopic adrenalectomy is the therapeutic modalities for adrenal adenoma and transsphenoidal pituitary microsurgery for pituitary adenoma. Although the ideal timing for surgery is still in debate, the early second trimester is considered to be optimal by most surgeons [3]. In the third trimester, conservative treatment and early delivery was preferred [1]. In case of nonsurgical treatment, metyrapone is the first choice of the drugs, as ketoconazole has proved to be teratogenic and embryotoxic in animal studies [9].

\section{References}

1. Chang I, Cha HH, Kim JH, Choi SJ, Oh SY, et al. (2013) Cushing syndrome in pregnancy secondary to adrenal adenoma. Obstet Gynecol Sci 56: 400-403.

2. Katulski K, Podfigurna-Stopa A, Maciejewska-Jeske M, Ruchala M, Gurgul E, et al. (2014) Cushing's syndrome in pregnancy: a case report and mini review of the literature. Gynecol Endocrinol 30: 345-349.

3. Blanco C, Maqueda E, Rubio JA, Rodriguez A (2006) Cushing's syndrome during pregnancy secondary to adrenal adenoma: metyrapone treatment and laparoscopic adrenalectomy. J Endocrinol Invest 29: 164-167.

4. Lekarev O, New MI (2011) Adrenal disease in pregnancy. Best Pract Res Clin Endocrinol Metab 25: 959-973.

5. Buescher MA, McClamrock HD, Adashi EY (1992) Cushing syndrome in pregnancy. Obstet Gynecol 79: 130-137.

6. Aron DC, Schnall AM, Sheeler LR (1990) Cushing's syndrome and pregnancy. Am J Obstet Gynecol 162: 244-252.

7. Woo I, Ehsanipoor RM (2013) Cabergoline therapy for Cushing disease throughout pregnancy. Obstet Gynecol 122: 485-487.

8. Hana V, Dokoupilova M, Marek J, Plavka R (2001) Recurrent ACTHindependent Cushing's syndrome in multiple pregnancies and its treatment with metyrapone. Clin Endocrinol (Oxf) 54: 277-281.

9. Xu JJ, Wang YJ, Shan LZ, Gu W, Zeng WH (2013) Recurrent ACTHindependent Cushing's syndrome in multiple pregnancies. Gynecol Endocrinol 29: 309-310.

10. Polli N, Pecori Giraldi F, Cavagnini F (2003) Cushing's syndrome in pregnancy. J Endocrinol Invest 26: 1045-1050.

11. Kamoun M, Mnif MF, Charfi N, Kacem FH, Naceur BB, et al. (2014) Adrenal diseases during pregnancy: pathophysiology, diagnosis and management strategies. Am J Med Sci 347: 64-73.

12. Lansdown A, Rees DA (2011) Endocrine oncology in pregnancy. Best Pract Res Clin Endocrinol Metab 25: 911-926.

13. Chui MH, Ozbey NC, Ezzat S, Kapran Y, Erbil Y, et al. (2009) Case report: Adrenal LH/hCG receptor overexpression and gene amplification causing pregnancy-induced Cushing's syndrome. Endocr Pathol 20: 256-261.

14. Nieman LK, Biller BM, Findling JW, Newell-Price J, Savage MO, et al. (2008) The diagnosis of Cushing's syndrome: an Endocrine Society Clinical Practice Guideline. J Clin Endocrinol Metab 93:1526-1540.

15. Lindsay JR, Jonklaas J, Oldfield EH, Nieman LK (2005) Cushing's syndrome during pregnancy: personal experience and review of the literature. $\mathrm{J}$ Clin Endocrinol Metab 90: 3077-3083.

16. Carr BR, Parker CR Jr, Madden JD, MacDonald PC, Porter JC (1981) Maternal plasma adrenocorticotropin and cortisol relationships throughout human pregnancy. Am J Obstet Gynecol 139: 416-422.

17. Chiodini I, Losa M, Pavone G, Trischittal V, Scillitani A (2004) Pregnancy in Cushing's disease shortly after treatment by gamma-knife radiosurgery. $J$ Endocrinol Invest 27: 954-956. 